\title{
UM DEVIR-VALÉRIA
}

\author{
"BECOMING-VALÉRIA"
}

\begin{abstract}
RESUMO
"Devir-Valéria” objetiva colocar em cena a escritora Maria Valéria Rezende: mulher, missionária e nos idos dos seus 76 anos. Buscou-se, neste artigo, captar os afetos que atravessam o seu ofício de escrever por meio de um corpo expressivo desses afetos. $\mathrm{O}$ encontro com a autora dispara devires que movimentam uma escrita liberta de uma narrativa linear e, também, de uma representação que cria um distanciamento entre as autoras e a escritora. Apresentou-se as relações de forças em luta e a potência de afetar e ser afetada da escrita-corpo-vida de Maria Valéria. Trata-se, pois, de uma questão de devir, em que forças outras são liberadas no percurso do envelhecimento e da velhice na vida missionária da escritora e na sua literatura. A linguagem poética adotada visa apreender a vibração das afecções que contagia o corpo da escritora e das autoras. Uma linguagem do pathos, livre da lógica da representação, constitui a opção experimental desse artigo.
\end{abstract}

Palavras-chave: Envelhecimento. Literatura Brasileira Contemporânea. Maria Valéria Rezende.

\begin{abstract}
"Becoming-Valéria" intends to point out the production of the novelist Maria Valéria Rezende: a 76 years-old catholic missionary. The aim of this paper is to capture the affections that cross her craft of writing through an expressive body of these affections. The meeting with the author encourages a movement that starts a writing freed from a linear narrative and also from a representation that creates a distance between the authors and the writer. The relations of forces in struggle and the power to affect and to be affected of Maria Valéria's writing-body-life were presented. That's a question of becoming, in which other forces are released in the course of aging and old age in the writer's missionary life as well as in her literature. The poetic language adopted has apprehended the vibration of the affections that infected the body of the writer and the author. A language of pathos, free from the logic of representation, is the experimental option of this paper.
\end{abstract}

Keywords: Aging. Contemporary Brazilian Literature. Maria Valéria Rezende.

Maria A. Demasi

Doutoranda em Ciências Sociais PUC-SP. Bolsista CNPq. E-mail: tonhademasi@gmail.com

Silvana M. C. Tótora

Professora do Departamento de Política e dos Programas de Pós-Graduação em Ciências Sociais e de Gerontologia da PUC-SP. E-mail: silvanatotora@gmail.com 
“[...] eu quero é entender ou desistir de entender de uma vez por todas. Escrever para entender ou esquecer [...]"

Maria Valéria Rezende, Quarenta Dias.

\section{Introdução}

Ao longo do artigo, a velhice é abordada através de autores que operam o tema como acontecimento, resistência e invenção.

A obra e a vida da escritora Maria Valéria Rezende são capazes de indicar respostas, caminhos e uma possível ética e uma estética do envelhecer. Os filósofos Gilles Deleuze e Giorgio Agamben são, então, convocados para reflexão, atualizando a velhice como dobra do tempo do acontecimento. A leitura do artigo é, desse modo, um convite a uma aproximação potente e pulsante do leitor à sua própria e única velhice.

\section{O escrever de uma velhice potente}

Coça.

Coça sem parar.

Levanta o vestido de tecido leve - quase uma camisola - e coça.

Coça com os dez dedos de suas duas velhas e aflitas mãos, que desejam com movimentos certeiros aplacar a sensação que a consome.

Aplacar o que é implacável.

Dante (2017: 121; canto XXII, verso 92), que Maria Valéria Rezende já leu e releu, pune os falsários com a grande fúria da coceira sem fim. Mas ela não conta com o fim desse suplício: bem sabe, depois de meio século perambulando mundo afora como missionária e educadora popular ${ }^{1}$, que há momentos da nossa experiência em que o caminho é desobstruir aquilo que atravanca nossa potência de vida.

Setenta e seis anos de vida intensamente vivida e uma velhice que resiste a sucumbir frente a dispositivos de poder que tentam, a todo momento, impedi-la de desfrutar livremente "esse tempo entre a vida e a morte". Apropriamo-nos, aqui, de uma ideia de Deleuze e Guattari:

Há casos em que a velhice dá, não uma eterna juventude, mas, ao contrário, uma soberana liberdade, uma necessidade pura em que se desfruta de um momento de graça entre a vida e morte, em que todas as peças da máquina se combinam para enviar ao porvir um dardo que atravesse as eras [...] (Deleuze \& Guattari, 1993: 09).

1 Desde 1965, Maria Valéria Rezende é missionária da Congregação de Nossa Senhora - Cônegas de Santo Agostinho. 
Maria Valéria Rezende é escritora.

Uma velha escritora.

Uma velha escritora velha.

Da casa de Santos onde nasceu, carrega a lembrança dos livros que circulavam pelos cômodos, passando pelas mãos das crianças, dos adultos, dos amigos dos adultos e de todos que fizessem gosto de sentar na varanda da casa, ler, e depois, contar.

Na casa de João Pessoa onde mora, guarda a memória do todo vivido, do todo contado, e experimenta, involuntariamente, sensações corporais peculiares que a arrastam para outros "lugares".

Comichões.

Pruridos.

Formigueiros.

Coceiras.

Intensidades.

Maria Valéria não se furta a viver nesse terreno movediço:

[...] a literatura aparece, então, como um empreendimento de saúde: não que o escritor tenha forçosamente uma saúde de ferro, [...] mas ele goza de uma frágil saúde irresistível, que provém do fato de ter visto e ouvido coisas demasiado grandes para ele, fortes demais, irrespiráveis, cuja passagem o esgota, dando-lhe contudo devires que uma gorda saúde dominante tornariam impossíveis (Deleuze, 1997: 14).

"Sei o que é, e de onde vem essa coceira!"

Ela está à espreita e assim, entre um momento torturante e outro de alívio, acende um cigarro e declara: "é emocional".

Um corpo que é afetado por ideias, encontros e desencontros com outros corpos a expurgar o que não deseja na forma de um dos sintomas físicos mais torturantes que uma pessoa pode experimentar: a coceira.

Inventar uma maneira de transmutar o que faz coçar em substantivos, verbos, frases, parágrafos, histórias:

[...] só então a linguagem perde o seu caráter de indigência reduzida à necessidade de comunicação e acordo da vida gregária para poder dançar com a vida: brincar com as palavras, uma bela doidice. As palavras e sons encontram a dimensão estética da vida, separadas pela linguagem do conhecimento e da moral: vontade de verdade e correção da vida' (Tótora, 2015: 148). 
Instalou-se um acontecimento como devir: tempo de renovação, tempo de resistir.

Giorgio Agamben (2018: 6o), ao refletir sobre o ato da criação, resgata uma entrevista concedida por Deleuze em 1988 a Claire Parnet ${ }^{2}$, em que afirma que "resistir significa sempre liberar uma potência de vida que estava aprisionada ou ultrajada”.

A linha do tempo cronológico de Maria Valéria pode ser descrita como uma sucessão na qual o resistir fez-se sempre presente.

Muitos e diversos encontros vida afora. Viveu de sertão em sertão, de país em país, de continente em continente, foi, como costuma dizer, "fermento" para um povo que, como reflete Deleuze, "precisamente, não é um povo chamado a dominar o mundo. É um povo menor, eternamente menor, tomado num devir-revolucionário. Talvez ele só exista nos átomos do escritor, povo bastardo, dominado, sempre em devir, sempre inacabado" (Deleuze, 1997: 15).

Meio século afetando e sendo afetada por miríades de vidas e mortes que determinam seu envelhecer, seu escrever, seu contar.

"Outros Cantos".

Um corpo mutante a se desterritorializar e territorializar em escritas potentes.

Uma narrativa a partir de paisagens mentais na qual a experiência dos fatos narrados não é essencialmente necessária para os leitores, e sim, os devires que se descolam da linguagem engendrada por Maria Valéria.

Depois de meu longo périplo, praticamente sozinha, por três continentes, acreditava-me pronta para tudo. Saberia, sim, abrir uma frente de inserção, preparar pacientemente a vinda dos demais [companheiros comunistas] para fermentar, por longo tempo, a consciência, a organização, a longa luta, verdadeiramente popular, de baixo para cima, alastrando-se pouco a pouco por todo o país e o continente, contra todas as formas de opressão (Rezende, 2016: 105).

Essa é a história de Maria. História misturada com a de outra Maria, Maria Valéria, essa, capaz de articular no seu fazer literário uma espécie de memória móvel, que determina seu presente.

Até eu ter 60 anos eu era uma educadora popular invisível, enfiada pelos lugares, inclusive porque a invisibilidade era uma condição para poder fazer o trabalho: você não toma a frente do povo, você anima, até que o pessoal pega seu impulso, e então você vai pra outro canto, você só é fermento na massa. ${ }^{3}$

2 Transcrição do áudio do vídeo disponível em: http://stoa.usp.br/prodsubjeduc/files/262/1015/ Abecedario+ G.+Deleuze.pdf.

3 Depoimento gravado em vídeo por Maria Antonia Demasi, em outubro de 2018, na residência de Maria Valéria, em João Pessoa. 
E com essa receita de vida, Maria Valéria seguiu, até 2003 quando seu corpo segredou que já estava cansado e era hora de contar.

Para ela, a literatura é o lugar de testar a todo momento sua potência de vida.

E desde sempre foi assim.

Conta.

Coça.

Escreve.

Desencosta.

Coça.

Volta a escrever.

[...] eu devia ter feito tudo ou pelo menos muito do que desejava nesta vida [...] quem sabe ainda é tempo de romper alguns desejos por cumprir? (Rezende, 2014: 31)

Sim!

Maria Valéria responde à pergunta de Alice, protagonista de Quarenta dias, construindo e dando voz ficcional a todas mulheres que, como ela, inventam a velhice.

E no agora, a autora velha trabalha no entretempo da saúde e da doença esticando a todo momento a corda das intensidades, sabendo que tudo - ou nada - pode acontecer.

Acontecimentos.

Esquecimentos.

Maria Valéria percebe a decadência do corpo. Ela esquece, e faz desse esquecer potência criativa. Não se esquece nunca de imaginar: "se o esquecido não está mais na minha cabeça, logo sobra mais espaço para minha imaginação!”.

Contrariando a máxima corrente de que envelhecer é perder vitalidade, Maria Valéria escreve cheia de vida mais de um livro ao mesmo tempo, articula com centenas de mulheres escritoras Brasil - o Mulherio das Letras, coletivo que luta por mais espaço no mercado editorial brasileiro, majoritariamente masculino —, cria mirabolantes roteiros de filmes, e já ganhou dois dos mais importantes prêmios de Literatura no Brasil4.

4 Maria Valéria recebeu os seguintes prêmios: Altamente Recomendável da FNLIJ, 2007, por Modo de apanhar pássaros à mão; Prêmio Jabuti, Câmara Brasileira do Livro, Literatura Infantil, 2009, por No Risco do Caracol; Finalista do Prêmio Jabuti, Câmara Brasileira do Livro, Categoria Juvenil, 20o9, por Conversa de Passarinhos e Ouro Dentro da Cabeça - 3ํㅡㄴ Lugar, Categoria Juvenil - Prêmio Jabuti, CBL 2013; Prêmio Jabuti, Câmara Brasileira do Livro: Quarenta dias - 1o Lugar, Categoria Romance - 2015; Prêmio Casa de Las Américas - categoria Literatura Brasileira - 2017, por Outros Cantos; Prêmio São Paulo de Literatura 2017 - categoria Melhor Livro de Romance do Ano, por Outros Cantos. 
No mundo e para o mundo lança luz sobre questões caras ao feminismo rindo das matérias jornalísticas que insistem em trazer manchetes reducionistas e capengas sobre sua trajetória profissional: "Maria Valéria Rezende, a freira escritora e feminista".

Não.

Para ela a manchete deveria ser: "Maria Valéria Rezende e sua potência de inventar".

Reinventar-se através da criação literária.

"Inventou" Alice, uma velha professora aposentada que se percebe capturada pelos discursos hegemônicos que clamam pelo cumprimento de deveres intrínsecos aos velhos para com os filhos adultos: cuidar! continuar cuidando até o apagamento final de sua subjetividade.

Na narrativa engendrada em Quarenta dias, essa armadilha é desarmada pela velha senhora candidata forçada à função de avó: [...] "ela resiste às formas atuais de sujeição, seja a um poder que individualiza, identifica e gere a vida da coletividade de modo geral, e de cada um em particular, seja a um saber que congela as singularidades e diferenças em uma identidade sabida e conhecida" (Tótora, 2015: 91).

Maria Valéria é mais que uma mulher comprometida com os princípios da instituição religiosa à qual se vinculou ainda muito jovem. É mais que uma velha missionária, é uma mulher que ao longo dos anos vem construindo de maneira peculiar uma ética da velhice que difere de

[...] uma concepção moral que codifica as condutas pelo dever (o que se deve ou não fazer para se ter uma velhice saudável, sem doenças), e mais, de um dever que emana de uma instância de representação que traça diretrizes programáticas e normas de caráter universal com pretensão de tolher e controlar o inesperado, ou experimentos prazerosos: ser velho, nessa perspectiva, é sempre estar privado de algo [...]. A ética, diferentemente, pressupõe a liberdade de construção do que se 'pode' ou não fazer, segundo potências singulares. $\mathrm{O}$ que pode a velhice? Trata-se de uma questão ética ou de potência (Tótora, 2015: 60).

O que pode essa septuagenária?

Essencialmente pode honrar a pulsão criativa que carrega desde sempre. E, disso, não abre mão.

Acompanhar Maria Valéria num verdadeiro "passeio cultural” por seu espaço de trabalho, nos confere a exata medida de sua relação com a memória decalcada em livros, cartas, moedas dos lugares por onde passou, fotografias amareladas, rolhas de bebidas com as quais brindou a vida e, por fim, nos faz descobrir que o afeto é o fio que alinhava sua trajetória.

Por tanto ter andado, e apesar de tanto já ter deixado para trás, Maria Valéria tem espalhado por sua casa fragmentos de uma vida repleta de encontros e que se 
materializam nos mais diversos objetos: cartões de telefone dos países onde viveu, cartas, cartões postais, buttons de movimentos sociais e campanhas políticas, bibelôs, folhetos e sempre a tensão entre a ordem desejada e a desordem reinante.

Nas estantes, lado a lado, livros de amigos, conhecidos e nem tanto, clássicos da literatura, edições raras e autografadas, manuscritos à espera da escritora que procura tempo para ler o que ainda não leu e reler o que muito gostou.

Na cabeça, ideias e mais ideias para novos livros. A coleção que guarda de pequenos cadernos de anotações carrega um rememorar de tempos vividos, e hoje esses fragmentos são revisitados incessantemente pelas mãos da escritora que segue remontando histórias.

Tudo é material para a criação ficcional de Maria Valéria: cada livro empoeirado, cada pedaço de papel, cada item desse colecionismo amador por ela praticado tornase um pedaço do todo que está sempre em processo em sua mente. Escrever para a ela é fazer ver o seu mundo.

Mundo que por ela é percebido de maneira análoga à de Maria, a personagem que muitos apontam como seu alter ego - afirmação que considera rasa e ingênua.

Não quero mais correria, pressa, velocidade... Ultimamente ando irritadiça e exausta, resisto, mas sou sempre arrastada pela pressa dos outros desde que a gente passou a viver, se mover, se informar, pensar e se comunicar com o máximo de velocidade possível segundo os diários e ruidosos lançamentos de novas geringonças eletrônicas, prometendo cada vez mais velocidade. Não é só o fastfood no estômago, é o fast-talking, fast-answering, fast-reading. Parece um complô para me obrigar a ser cada vez mais fast, em tudo, a ser avaliada e a me avaliar pela minha rapidez de resposta e atualização. Ave! E quem pode, assim, continuar a ser gente, ter juízo e saúde? (Rezende, 2016: 72)

Ao reiterar o desejo de experimentar a vida na sua intensidade e não na velocidade imposta por um conjunto de "micropoderes" forjados pelo neoliberalismo, a velha escritora se distancia das pressões de seu tempo e afirma seu lugar num campo de intensidades fora de todos os enquadramentos: o hoje de Maria Valéria é lento e no compasso que seu corpo estabelece. Se não mais enxerga com os dois olhos, se ajeita apenas com a visão oferecida por um, se não mais pode subir na árvore para apanhar acerolas, consegue alcançar as frutas chacoalhando os galhos, se não pode mais dirigir, aceita as caronas dos amigos, se não que falar sobre algo, se cala.

Deleuze, ainda na entrevista a Parnet, afirmou que “[...] o velho é alguém, que adquiriu o direito de ser [...]. Ele está livre de projetos [...]. Caem todos os parasitas [que se] carregou a vida inteira [...] [reúne a sua volta] as pessoas que ama e que o suportam e o amam também [...]. Um velho simplesmente, que é apenas velho, é o ser"s.

5 Transcrição do áudio do vídeo disponível em: http://stoa.usp.br/prodsubjeduc/files/262/1015/ Abecedario+G.+ Deleuze.pdf. 
E é assim que Maria Valéria percebe seu envelhecer:

Tem uma vantagem da gente ter 76 anos, já para lá de Marrakesh, com stent no coração : eu não tenho nada a perder, nada a perder... eu estou aqui desde antes a bomba de Hiroshima, antes da penicilina, quando a gente morria de furúnculo, panarício, sífilis, eu estou aqui desde esse tempo a... ${ }^{6}$

Viver

Contar

Escrever

Coçar

O tempo por ela vivido e os desgastes inerentes a esse tempo foram muito menos intensos do que as experiências registradas em sua memória. Foram décadas de estudos no campo das teorias sociais e antropológicas, do universo religioso, das cinco línguas que domina, dos cânones da literatura. E foram as mesmas tantas décadas aprendendo, penetrando no que já estava pronto, buscando singularidades nas vidas em que esbarrava, nas lutas que enfrentava, nas diferenças, nas desigualdades, na miséria e, assim, fruir na potência da vida que escolheu viver.

Gonçalo Tavares, escritor português que dialoga com a filosofia afirma que

[...] na memória que trabalha diretamente com o imaginário o que importa não é tanto a veracidade, mas a intensidade. Não importa se foi assim que aconteceu, importa sim, se a memória relatada excita, influencia, se sacode o ouvinte e o engrandece. Quando se narra uma história imaginativa (com auxílio da memória enquanto ficção inconsciente) o que importa são os efeitos dessa história no mundo que aí vem, não a proximidade aos fatos do mundo que já foi e já não existe (Tavares, 2013: 375).

E justamente por assim ser, foi chegada a hora dessa velha escritora misturar, mais uma vez, memória e imaginação para contar um pouco da história de um país — teoria e prática - que ela tão bem conhece.

\section{"Carta à Rainha Louca”}

1789 .

O resgate de um devir-mulher: um corpo que foi "roubado" por homens carentes e desejosos de possuir os corpos femininos.

6 Depoimento gravado em vídeo por Maria Antonia Demasi, em março de 2019, na residência de Maria Valéria, em João Pessoa. 
Isabel atravessou a vida como prisioneira do mundo religioso. Seus dias foram contornados por promessas de epifanias e liberdade, que nunca foram alcançadas. Ao contrário, o tempo, vasto tempo, somente tratou de presenteá-la com mais rigidez de códigos e normas de conduta.

Eis que a mulher prisioneira de um convento pernambucano descobre que escrever seria sua forma de resistir: qualquer superfície que aceitasse tinta, qualquer tinta, era receptáculo para reter todos instantes de seu passado, e a possibilidade de continuar viva por apenas uma amanhã que fosse a fez acreditar no futuro, tempoespaço onde sua resistência ecoaria através da carta que desde muito escreve para a rainha de Portugal.

Devo confessar-Vos, Majestade, que muitas vezes duvido de quem sou, duvido de minhas lembranças, já não sei se são verdade ou alucinações, e temo que tudo o que tenho imaginado como se meu passado fosse, até mesmo em parte belo em minha recordação como por vezes me parece, não seja senão o meu desejo de que assim tivesse sido. Prossigo, no entanto, minha Senhora, porque isto de não se saber ao certo quem é cada pessoa, como vejo por toda parte aqui nesta terra do Brasil, há de ser cousa comum também nas galerias de Vossos paços em Portugal e em todos os Vossos reinos - como aprendi dos livros proibidos que lie dos infortúnios que me fez passar Diogo de Távora. Por certo que também ali se cruzam e troeam vênias as pessoas consideradas de qualidade, sem nenhuma prova de que o são, tanta éa hipoerisia, o adultério, a mentira, a traięão, a lisonja, ofingimento, a aleivosia, a devassidão, o suborno a corrupęão que por eles cam- peiam sinto e sei que a única cousa que me pode manter sã a mente, de sorte que eu não naufrague para sempre no mar encapelado dos meus delírios, é o esforço de ordenar as palavras em meu pensamento e no papel, não importando para nada se são verdadeiras — daquela verdade que querem os inquisidores e os juízes — ou se são apenas a verdade do meu desejo e do meu sonho, da liberdade de pensar, que outros consideram insanidade, mas que teima em medrar no mais recôndito de qualquer mulher até mesmo em Vós que, sendo rainha, por natureza nada mais sois que uma fêmea faminta de amor e de horizontes, como todas nós outras, porque assim creio estarem feitos o Vosso corpo e o Vosso coração como os nossos, e deles emanarem os mesmos humores, a não ser que Vos hajam mutilado e oprimido desde o Vosso naseimento para toreer-Vos a natureza e fazer de uma simples mulher uma princesa perfeita, o que não ereio, pois se assim fosse, haveríeis de enlouqueeer, Vós também, sendo por certo muito mais de perto vigiada do que nós que nada valemos. (Rezende, 2019: 50) ${ }^{7}$

7 No romance de Maria Valéria o texto aparece grafado desta maneira, tachado, como se houvesse sido rasurado pela personagem-narradora em sua carta-narrativa. 
Escrever para não enlouquecer. Para escancarar o não-lugar histórico das mulheres.

Tentar apagar para ser suportável o encontro com o indigno de uma vida. Diversos trechos do livro estão riscados, marca da tentativa de Isabel de não dizer o que não pode ser calado.

No entretempo do naufrágio de uma vida e uma história a ser contada, Isabel teme o delírio. Deleuze, ao refletir sobre a literatura e a vida, afirma que a primeira é delírio e que

[...] o delírio é uma doença, a doença por excelência a cada vez que erige uma raça pretensamente pura e dominante. Mas ele é a medida da saúde quando invoca essa raça bastarda oprimida que não para de agitar-se sob as dominações, de resistir a tudo o que esmaga e aprisiona e de, como processo, abrir um sulco para si na literatura (Deleuze, 1993: 15).

Escreve.

Apaga.

Coça.

Maria Valéria segue se coçando. Sabe que tem a grande saúde. Sabe que esse acontecimento em seu corpo é um devir, o devir-envelhecer, esse entretempo em que tudo pode acontecer. Inclusive a morte.

\section{Considerações finais}

Maria Valéria Rezende é potência de vida.

Aponta para o envelhecimento como uma obra de arte em construção e, portanto, se aproxima das intensidades possíveis deste tempo.

A obra literária da escritora se alinha pois, a esse trajeto e se compõem para intensificar esse devir-Valéria.

\section{Livros Publicados por Maria Valéria Rezende}

Vasto Mundo - 2001

O Voo da Guará Vermelha - 2005

Modo de Apanhar Pássaros à Mão - 2006

O Arqueólogo do Futuro - 2006

Conversa de Passarinhos - 2008

No Risco do Caracol - 2008 
Histórias daqui e d’acolá - 2009

Hai-Quintal - 2012

Planeta Vampiros e outros sustos - 2013

Uma Aventura Animal - 2013

Quarenta Dias - 2014

Outros cantos - 2016

A face serena - 2017

Histórias nada sérias - 2017

Carta à Rainha Louca - 2019

\section{Referências}

ALIGHIERI, Dante. (2017). A Divina Comédia - Vol. 1: Inferno. Tradução de Xavier Pinheiro. Introdução de Otto Maria Carpeaux. 12 $2^{\mathrm{a}}$ ed. Rio de Janeiro: Nova Fronteira [1321]. Recurso digital [formato ePUB].

AGAMBEN, Giorgio. (2018). O Fogo e o Relato: ensaios sobre criação, escrita, Arte e livros. Tradução de Andrea Santurbano e Patricia Peterle. São Paulo: Boitempo Editorial.

DELEUZE, Gilles. (1993). O que é filosofia? Tradução de Bento Prado Jr. e Alberto Alonso Muñoz. Rio de Janeiro: Editora 34.

DELEUZE, Gilles. (1997). Crítica e Clínica. Tradução de Peter Pál Pelbart. São Paulo: Editora 34.

REZENDE, Maria Valéria. (2014). Quarenta dias. Rio de Janeiro: Alfaguara.

REZENDE, Maria Valéria. (2016). Outros cantos. Rio de Janeiro: Alfaguara.

REZENDE, Maria Valéria. (2019). Carta à Rainha Louca. Rio de Janeiro: Alfaguara.

TAVARES, Gonçalo. (2013). Atlas do Corpo e da Imaginação: Teoria, Fragmentos e Imagens. Alfragide: Editorial Caminho.

TÓTORA, Silvana. (2015). Velhice: uma estética da existência. São Paulo: Educ; FAPESP. 